\title{
Molecular Docking Study of Biologically Active Ligand and the Insights of Synthesis, Characterization and In Vitro Studies of Derivatives of $\beta$-tubulin Polymerization Inhibitor as Antigout Agent
}

\author{
Vaishali H. Gaikwad ${ }^{1, *}$, Kailash R. Borude², B.C. Khade² and \\ Vaibhav B. Sabale ${ }^{3}$ \\ 1Department of School of Chemistry, MITWPU, Pune 411038, Maharashtra, India \\ 2Department of Chemistry, K.K.M. College, Manwat, Parbhani 431505, Maharashtra, \\ India \\ 2Department of Chemistry, Dnyanopasak Sciences College, Parbhani 431401, \\ Maharashtra, India \\ ${ }^{3}$ Department of Biotechnology, School of Life Sciences, Kavayatri Bahinabai \\ Chaudhari North Maharashtra University, Jalgoan 425001, Maharashtra, India
}

Article Type: Article

Article Citation: Vaishali H. Gaikwad, Kailash R. Borude, B.C. Khade, Vaibhav B. Sabale. Molecular docking study of biologically active ligand and the insights of synthesis, characterization and in vitro studies of derivatives of $\beta$-tubulin polymerization inhibitor as antigout agent. Indian Journal of Science and Technology. 2020; 13(07), 756-766. D0l: 10.17485/ijst/2020/ v013i07/149615

Received date: December 12, 2019

Accepted date: February 1, 2020

*Author for correspondence: Vaishali H. Gaikwad vaishali. gaikwad@mitwpu.edu.in 9 Department of School of Chemistry, MITWPU, Pune 411038, Maharashtra, India

\section{Abstract}

Background/objective: The aim of the study is to synthesize derivatives of colchicine, which is an anti-gout drug, and to enhance the antimicrobial activity of it. As it is observed in case study of drugdrug interaction, i.e. Colchicine and clarithromycin, which is known as antimicrobial drug has given fatal results, in consequence to that we have tried to enhance the antimicrobial activity of the drug itself, as there is always a need of antimicrobial drugs in the treatment of gout. In addition, to study the binding of protein and colchicine through molecular docking. Methods/analysis: In this work, the detailed molecular docking study of colchicine has been done and complexes of colchicine with Co (II), Ti(II), Ni (II) Fe (II) Zn(II) Cu(II) are synthesized and investigated by using IR, and antimicrobial antifungal screening. Findings/application: Docking shows the exact binding site of the ligand which is beta-tubulin inhibitor. It is also observed that first transition series metal forms stable complexes with this ligand specially and shows enhanced antimicrobial activity.

Keywords: Colchicine Complexes, Molecular Docking, Gout, Beta Tubulin Inhibitor Antimicrobial Activity, IR. 


\section{Introduction}

Metals have an important place in medicinal chemistry. They have been used in the treatments of diseases since ancient time. In [1] the list of metals, transition metals are known to play very essential role in biological processes in the human body. Metal ions influence in the complexed form, particularly when the metal is necessary for the human body, complexed with the drug as discovery of new compounds having more antimicrobial, antioxidant, anti-inflammatory activities [2-4]. Colchicine which is also known as Mitigare acts as antigout, antimitotic, antifibrotic, anti-inflammatory drug as shown in Figure 1.

Gout is a common arthritis due to the deposition of monosodium urate (MSU) crystals within joints after a long-standing history of hyperuricemia [5]. Gout causes recurrent acute and very painful arthritis and can lead to joint destruction on the long term.

Excess uric acid in the blood is the basic reason of attack of gout disease. Increased uric acid forms needle like urate crystals which accumulates on joints causing the inflammation and intense pain [6] redness heat, of gout attack. Uric acid is the end product of purine metabolisms, taking food rich in purine, contributes to the total uric acid level.

A high protein diet typically contains large quantity of purine. Whey proteins may not be directly connected with gout. When kidneys do not eliminate optimum uric acid, uric acid level increases. Things that may cause this slowdown in the removal of uric acid are purine rich food, being overs weight, having diabetic, taking certain diuretics and drinking excess alcohol.

There are less evidences that gout can cause kidney diseases, but it can lead to kidney diseases. Hypertension is also another reason for hyperuricemia and gout. Increased systematic blood pressure results in reduced glomerular filtration rate which promotes to decrease glomerular blood flow and decreased excretion of UA. Though there is no direct connection between protein and gout observed yet but food like fish, red meat, sea food should be avoided.

Vitamin C was found to increase renal excretion of uric acid, so it can be used as a supplement during gout management. The normal fractional excretion of uric acid is $7 \%$ to $10 \%$. When it decreases, this reflects a reduction of uric acid excretion in increased serum urate level [7].

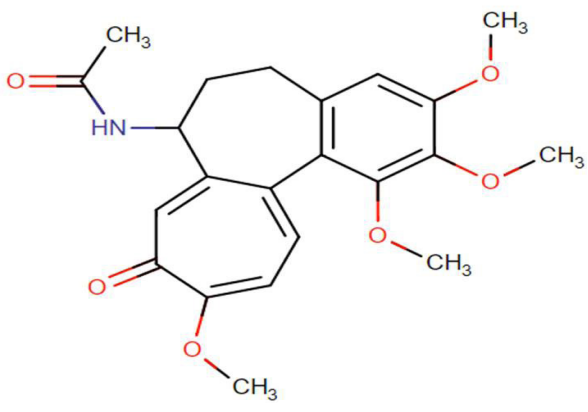

FIGURE 1. Structure of colchicine molecule. 
Gout specially attacks on the large joint of big toe, and also on joint like ankles, knees, elbows, etc. The general prevalence of grout is $1 \%$ to $4 \%$ of the general population.

\section{Mechanism of Action}

Colchicine is a tropolone alkaloid form autumnal used as gout suppressants and nonsteroidal anti-inflammatory agents (NSAIDs) [8-9].

It is derived from the dried seeds of colchicine autumnal known as meadow saffron [10], naturally occurs as neutral molecule, it does not form salts because of its very low basicity.

All that drugs which binds to human tubulin, binds to $\beta$-tubulin. These include padimate, colchicine, and vinca alkaloid. Colchicine is a tubulin polymerization inhibiter [11]. It binds to soluble tubulin to form tubulin colchicine complexes in a poorly reversible manner, which then binds to the ends of micro tubulin to prevent the elongation of the micro tubule polymer and that's why it is also known as anti-MT drugs (microtubules$\alpha$ - $\beta$-tubulindimer). It disrupts the polymerization of $\beta$-tubulin in to microtubules thereby preventing the activation, degranulation, and migration of neutrophils to sites of inflammation [12]. Microtubules have recognized as highly attractive sites of cancer chemotherapy. In spite of having a long history of characterization, colchicine has not reached to commercial phase as anticancer drug till date [13]. Colchicine is metabolized through cytochrome P450 3A4 (CYP3A4); therefore, administration with agents that inhibit this isoenzyme can produce elevated colchicine plasma concentrations, resulting in severe and sometimes fatal adverse events [14]. Knowledge of the potential for drug-drug interactions involving antibiotics (e.g., macrolide antibiotics, azole antifungals) allows pharmacists to help patients avoid serious adverse events. It is observed in a case study of FMF (Familial Mediterranean Fever) natural grape juice which is known as cytochrome P450 inhibitor, creates intoxication with colchicine because CYP450 is an enzyme required for metabolism of the drug. Inhibition of this enzyme creates increased level of drug without metabolism, which leads to intoxication. Co-administration of CYP3A4 inhibitors (particularly clarithromycin) and colchicine has given sever colchicine toxicity manifested by severe gastrointestinal toxicity, and fatal effect [15-16].

Another drug called allopurinol [17] which can also be used to decrease the urate serum level, but medical teaching suggests that allopurinol should not be initiated in the setting of an acute gout attack, because rapid lowering of serum urate may elevate the attack.

Not much study has been done on the formation of complexes between colchicine and cations. In the present work, we have chosen the metals like $\mathrm{Zn}, \mathrm{Ti}, \mathrm{Cu}, \mathrm{Fe}, \mathrm{V}$ Co-metal ion to make complexes, with colchicine and characterized cell and studied antimicrobial activities [18].

\section{Material and Methods}

Fundamentally, the objective of molecular docking is to give a calculation of the ligandreceptor complex structure using computation methods. Docking can be achieved through 
two organized steps: first by sampling conformations of the ligand in the active site of the protein; then standing these conformations via a scoring function. Ideally, sampling algorithms should be able to reproduce the experimental binding mode and the scoring function should also rank it highest among all generated conformations. From these two perspectives, we give a brief overview of elementary docking theory.

Docking was achieved by Auto dock 4.2.6 program, using the realized empirical free energy function and the Lamarckian Genetic Algorithm (LGA). The grid maps were calculated using Auto Grid. In all dockings, a grid map with $40 \times 40 \times 40$ points and a gridpoint spacing of $0.481 \AA$ was applied.

All chemicals used are analysis grade colchicine is commercially available. The salts of $\mathrm{Zn}\left(\mathrm{No}_{3}\right)_{2}, \mathrm{TiO}_{2}, \mathrm{Ni}\left(\mathrm{No}_{3}\right)_{2}, \mathrm{Cu}\left(\mathrm{No}_{3}\right)_{2}, \mathrm{~V}_{2} \mathrm{O}_{5}, \mathrm{FeCl}_{3}$ were obtained from Sigma-Aldrich. All the salts ligands are taken in the ratio of 2:1 and dissolved separately in ethanol and the mixed together; the reaction mixture is refluxed for $2 \mathrm{~h}$. The mixture is filtered and dried in over to obtain the powder. All most all complexes have shown the change in color. Before reaction the ligand was white in color after reaction with $\mathrm{CuNO}_{3}$ the color of the complex was green, with $\mathrm{Ni}\left(\mathrm{NO}_{3}\right)_{2}$ it was known for $\mathrm{TiO}_{2}$ the change observed it creamy in case $\mathrm{Zn}\left(\mathrm{NO}_{3}\right)_{2}$ it was similar i.e. with for $\mathrm{FeCl}_{3}$ it is reddish and for $\mathrm{V}_{2} \mathrm{O}_{5}$ it has shown green color. This changes in color in a must all complexes indication the first sign of complex formation [19-20].

\section{Results and Discussions}

Melting points are taken in open capillaries on a melting point apparatus. It observed that melting points of all complexes are above $350{ }^{\circ} \mathrm{C}$. Solubility of all complexes is checked; all are insoluble in water and partially soluble in DMSO. Infra-Red Spectra the harmonic vibrational study of some complexes is given below. In all heterocyclic compounds, $\mathrm{N}-\mathrm{H}$ stretching vibrations occurs in the reason $3500-3000 \mathrm{~cm}^{-1}$. In a present work, $\mathrm{N}-\mathrm{H}$ stretching vibrations are calculated at $3454 \mathrm{~cm}^{-1}$ for the parent ligand, and for the complexes prepared almost all complexes are showing decrease in the $\mathrm{N}-\mathrm{H}$ stretching vibrations as shown in Figures 2-4. The present ligand C-H stretching vibrations are observed at $3060 \mathrm{~cm}^{-1}$ and

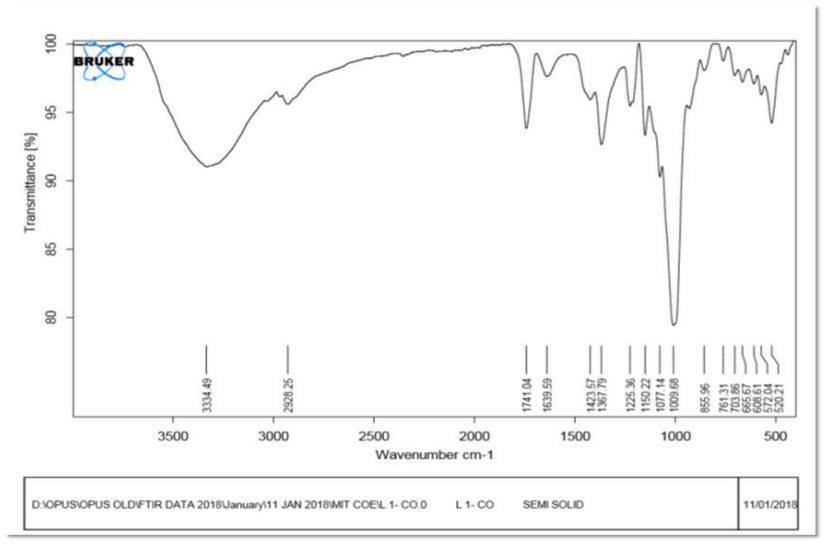

FIGURE 2. IR of colchicine-cobalt. 


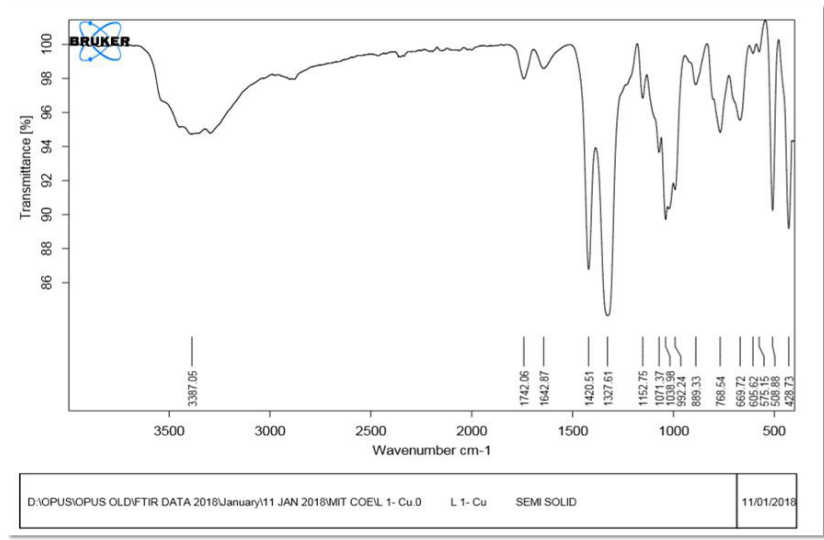

FIGURE 3. IR of colchicine-copper.

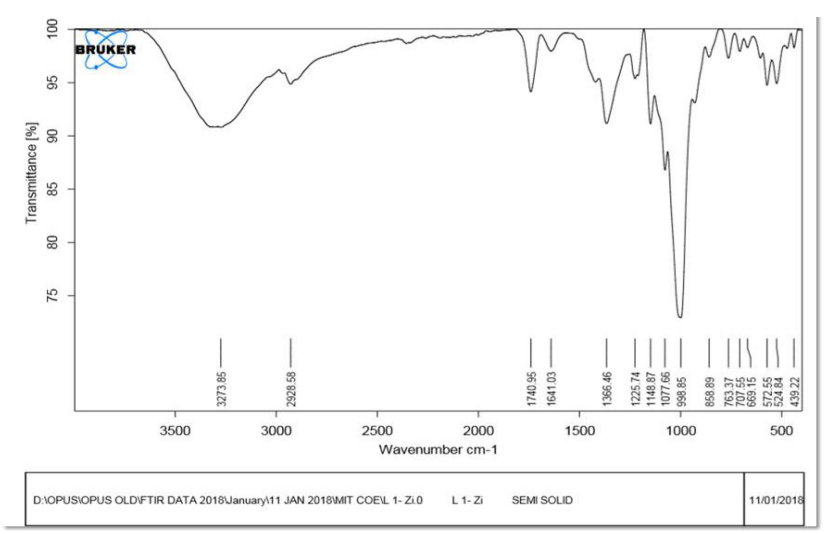

FIGURE 4. IR of colchicine-zinc.

there is no any major shift change in the vibrations. The same observation is obtained in case of $v \mathrm{C} 13=\mathrm{O} 4$, so this indicates that the donor groups are $\mathrm{N}-\mathrm{H}$ amino nitrogen (Table 1 ).

\subsection{Antimicrobial Activity Synthesized Compound}

By far the most widely used assays for identifying antimicrobial activity by diffusion methods, which exploit diffusion of antimicrobial compounds through agar media and

TABLE 1. $\mathrm{N}-\mathrm{H}$ stretching values of metal ligand complexes

\begin{tabular}{lcc}
\hline Compound & $\boldsymbol{v} \mathbf{N}-\mathbf{H ~ c m}^{-\mathbf{1}}$ & $\boldsymbol{v} \mathbf{M}-\mathbf{N ~ c m}^{-\mathbf{1}}$ \\
\hline Colchicine & 3454 & \\
{$[\mathrm{Co}($ Colchicine $)]$} & 3334 & 520 \\
{$[\mathrm{Fe}($ Colchicine $)]$} & 3273 & 436 \\
{$[\mathrm{Ti}($ Colchicine $)]$} & 3271 & 509 \\
{$[\mathrm{Ni}($ Colchicine $)]$} & 3266 & 431 \\
{$[\mathrm{Cu}($ Colchicine $)]$} & 3338 & 428 \\
{$[\mathrm{~V}($ Colchicine $)]$} & 3192 & 497 \\
\hline
\end{tabular}


demonstrate inhibition of bacteria and fungi. Variations on the underlying principles of agar diffusion have been in existence since the late. In fact, this principle was used by Alexander Fleming in interpreting his observations for the Penicillin consequently led to the discovery of the first antibiotic, Penicillin.

The use of agar diffusion continues into modern times in the antimicrobial assays recommended by the US Food and Drug Administration and the National Committee for Clinical Laboratory Standards. The basic idea of diffusion assays is as follows: a suspected antimicrobial compound or treatment is presented within a reservoir created on an inoculated plate of agar medium, zone of inhibition forms where concentrations of the diffused molecules are sufficient to inhibit microbial growth. On the surface, the theory is quite simple. Diffusion of antimicrobial compounds from a reservoir over time produces an outward gradient of decreasing concentration of the compound. Where concentration of the compound is sufficient to inhibit the growth of the microbes, the growth is blocked, resulting in the observed zone, which extends outward from the reservoir (with a corresponding decrease in concentration) to the distance from the reservoir at which the minimum concentration required for inhibition exists. The antimicrobial activity of C. zeylanica leaves extracts was evaluated of possible antibacterial and antifungal activity against selected strains for microorganisms.

\subsection{Preparation of Solutions of Synthesized Sample}

Before testing these samples for antimicrobial activity, they were completely dried at normal conditions. It was dissolved in DMSO and diluted with sterilized water, prepared the stock solutions of each sample of different concentrations.

\subsubsection{Positive Control}

Gentamycin and Clotrimazole are taken $10 \mu \mathrm{g} / \mathrm{ml}$ for each.

\subsubsection{Test Cultures}

For evaluation of antimicrobial activity, six cultures were used amongst which three were Gram positive bacteria, three were Gram-negative bacteria and two fungi (Table 2).

Gram positive bacteria: Staphylococcus aureus (NCIM-2901) and Bacillus subtilis (NCIM-2063)

Gram negative bacteria: Escherichia coli (NCIM-2256) and Klebsiela pneumoniae (NCIM-2957)

Fungi: Candida albicans (MTCC-3018) and Aspergillus niger (MTCC-404)

\subsection{Molecular Docking}

AutoDock V4.2 uses a computationally inexpensive "hybrid" force field that covers terms based on molecular procedure as well as experiential terms [21]. The calculation of absolute binding energies may be less precise compared to more computationally expensive, purely 


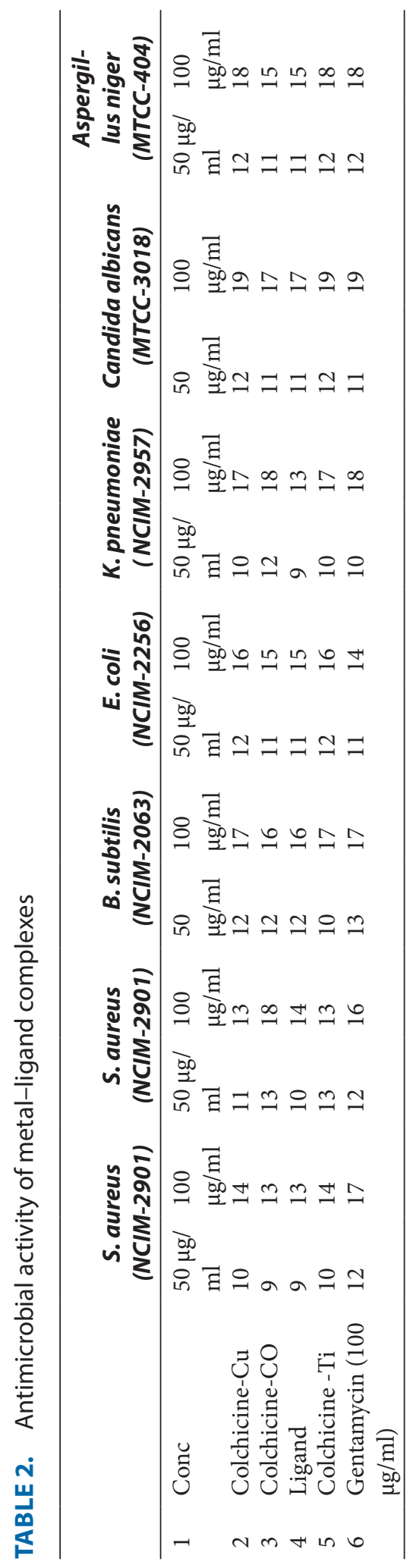


force field-based approaches, but this semi-empirical approach is measured as well-suited for the relative rankings as shown in Table 3.

The finest conformation with the lowest docked energy was selected from the docking search. The communications of complex protein-ligand conformations including hydrogen bonds and bond lengths were analyzed using Pymol software, UCSF Chimera, Molegro Molecular Viewer, and Accelrys DS Visualizer software.

The protein name is Beta Tubulin and Sequence Length is 444 . The protein Organism is Homo sapiens and Gene Names is TUBB5. The amino acid information of Beta Tubulin in which amino acids are 424 out of 444 (96\%), Favoured amino acid is 395 (93\%) and allowed amino acids is 29 (7\%). This information is related with Ramachandran plot.

On carrying out the docking of the $\beta$-tubulin (PROTEIN) with Ligand Colchicine and it was detected that the binding energy shown by the $\beta$-tubulin and ligand is good at $-8.557 \mathrm{kcal} / \mathrm{mol}$. This interaction is more stable as there is one hydrogen bonds formed at Arg164(H) (comparable binding energy, although lower binding energy indicates a good and stable communication). In conclusion, Ligand showed better results on docking with the protein. Estimated loss of torsional free energy upon binding energy is $+1.3720 \mathrm{kcal}$. Minimum electrostatic potential is -29.47 and maximum electrostatic potential is 30.19 as shown in Figures 5-7.

\section{Conclusion}

The structures of known biologically active molecules are altered to obtain the new molecules known as metal coordinated complexes. We have been established some of these novel complexes and also observed that their antimicrobial activity and fungicidal activity are enhanced, especially for $\mathrm{Cu}, \mathrm{Co}$, Ti than their parent ligand for Fe, $\mathrm{V}, \mathrm{Ni}$ it has not shown enhanced anti-microbial than their parent ligand i.e. Colchicine. Colchicine showed better results on docking with the $\beta$-tubulin. The mentioned ligand inhibits the elongation of $\beta$ tubulin. This study is useful in making metal colchicine complexes for better pharmaceutical results to treat gout.

TABLE 3. Summary of binding energy, site prediction, hydrogen bond and ligand docking information results using AutoDock V4.2 software

\begin{tabular}{|c|c|c|c|c|c|c|c|}
\hline $\begin{array}{l}\text { Protein } \\
\text { name }\end{array}$ & $\begin{array}{l}\text { Ligand } \\
\text { name }\end{array}$ & $\begin{array}{l}\text { Binding } \\
\text { energy } \\
\text { (kcal/ } \\
\text { mol) }\end{array}$ & $\begin{array}{l}\text { No. of } \mathrm{H} \\
\text { bonds }\end{array}$ & $\begin{array}{l}\text { Interacting } \\
\text { residue }\end{array}$ & $\begin{array}{l}\text { Electro- } \\
\text { static } \\
\text { energy } \\
\text { (Kcal/mol) }\end{array}$ & $\begin{array}{l}\text { VdW + H } \\
\text { bond+ } \\
\text { desolv } \\
\text { Energy }\end{array}$ & Resolution \\
\hline $\begin{array}{l}\text { B-tubulin } \\
\text { (tubulin } \\
\text { beta) }\end{array}$ & Colchicine & -8.557 & $\begin{array}{l}01 \\
(\text { Distance= } \\
3.36 \mathrm{~A}, \\
\text { strength = } \\
-1.22)\end{array}$ & $\begin{array}{l}\text { Glu127 } \\
\text { Arg164(H) } \\
\text { Tyr161 } \\
\text { Asp163 } \\
\text { Glu160 }\end{array}$ & $\begin{array}{l}\text { Minimum } \\
\text { electrostatic } \\
\text { potential } \\
=-29.47 \text {, } \\
\text { maximum } \\
\text { electrostatic } \\
\text { potential = } \\
30.19\end{array}$ & -70.62 & $3.6 \AA$ \\
\hline
\end{tabular}




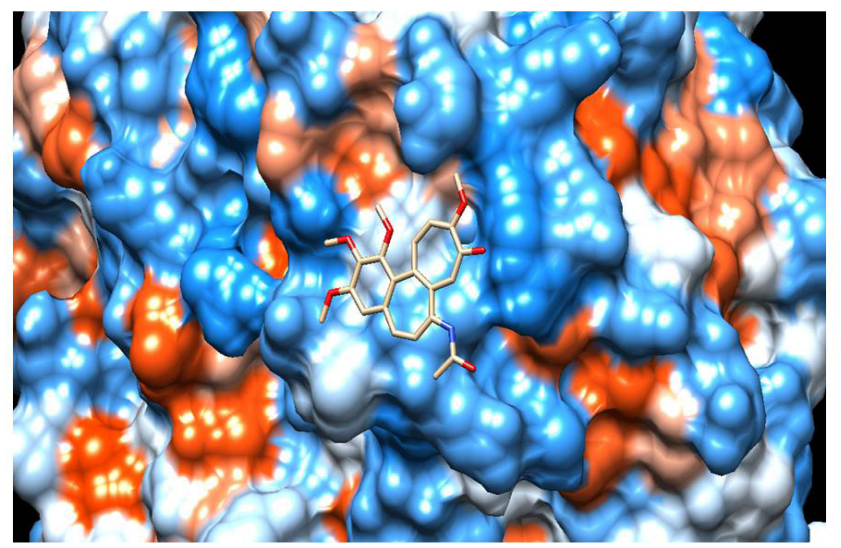

FIGURE 5. Electrostatic docking structure of beta tubulin protein and colchicine as a ligand compound.

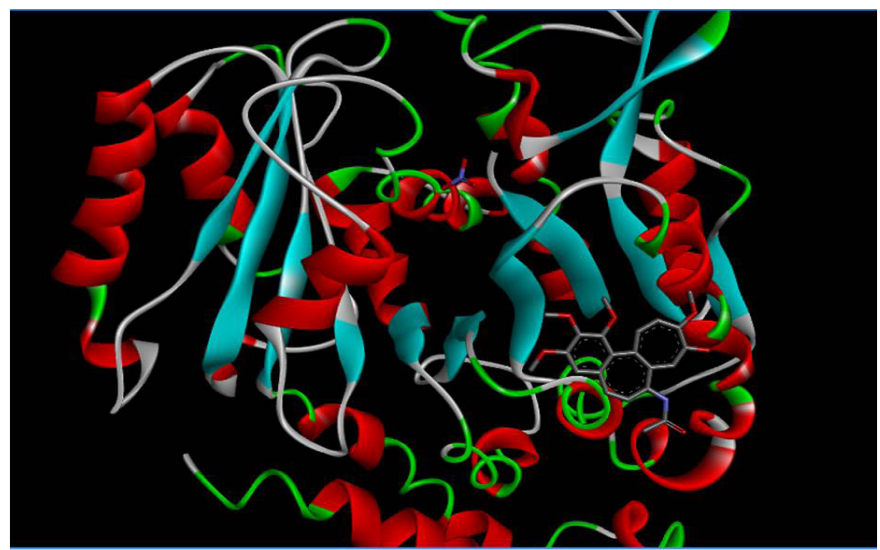

FIGURE 6. Complex and docking structure of beta tubulin protein and colchicine as a ligand compound.

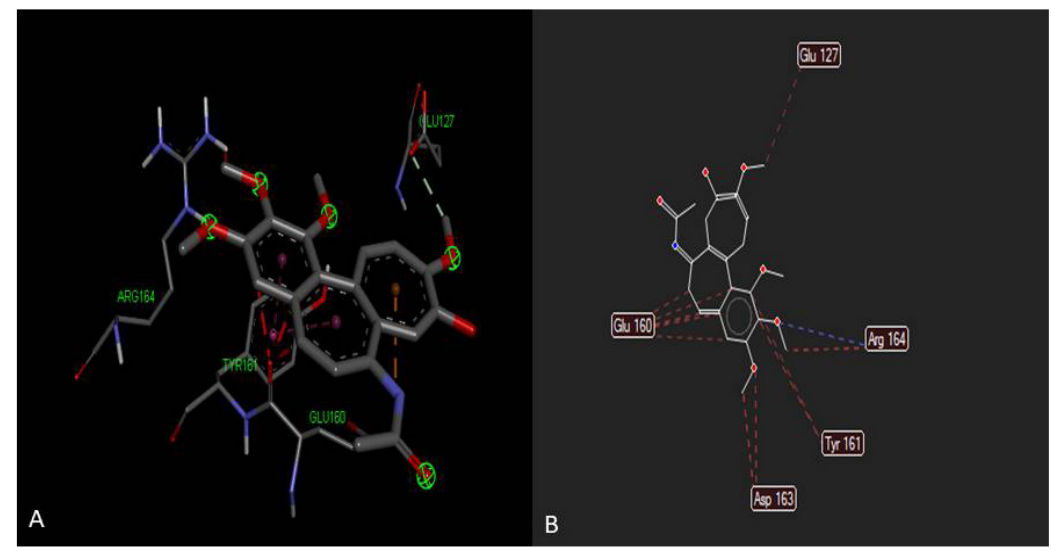

FIGURE 7. (A) Docking poses of the compounds colchicine with beta tubulin protein. (B) Binding interactions of colchicine and the beta tubulin protein (hydrogen bond interactions are indicated with blue dotted lines). 


\section{Acknowledgement}

The authors gratefully acknowledge Mrbiologist Pune (http://askmrbiologist.com/) for the support of computational analysis and Babbage computer lab school of pharmacy MITWPU, Pune.

\section{References}

1. Waziri I, Ndahi NP, Mala GA, Fugu MB. Synthesis, spectroscopic and biological studies of cobalt (II), nickel (II) and iron (III) mixed antibiotic metal complexes. Scholars Research Library Der Pharma Chemica, 2014, 6(5), 118-122. http://derpharmachemica.com/archive.html

2. Sarwade SS, Jadhav WN, Khade WN. Characterization of novel complex ciprofloxacin Ag (I). Scholar Research Library. 2015, 7(1), 36-41. https://pdfs.semanticscholar.org/71e8/6c58e40f370 03c5910b0353367dbfc682c8b.pdf

3. Khade BC, Sarwade SS, Korde NS, Pawar RP. Equilibrium studies on mixed ligand complex formation of antiparasitic drug sulphadoxine and some amino acids with chromium (III). Archives of Applied Science Research. 2015, 7(1), 36-41. http://scholarsresearchlibrary.com/ archive.html

4. Tayde D, Sarwade SS, Jadhav WN, Khade BC. A study on the complexes of transition metals with nitazoxanide. Scholars Research Library Archives of Applied Science Research. 2015, 7(1), 28-35. http://scholarsresearchlibrary.com/archive.html

5. BeckerMA, Perez-RuizF. Pharmacologicurate-lowering therapyand treatment of tophiin patients with gout. UpToDate. Waltham, MA: Licensed to: Upto Date Marketing Professional support Tag. 2018. https://www.uptodate.com/contents/pharmacologic-urate-lowering-therapyand-treatment-of-tophi-in-patients-with-gout

6. Pascart T, Richette P. Current and future therapies for gout. Expert Opinion on Pharmacotherapy. 2017, 18(12), 1201-1211. DOI: 10.1080/14656566.2017.1351945.

7. Lapian LG, Thobias GP, Maengkom AO. The influence of Boteme (Setaria Italica) Against A decrease in the levels of uric acid in sufferers gout arthritis in the village of Gamsungi sub district of Tobelo North Halmahera. International Journal of Health Medicine and Current Research. 2018, 3(02), 920-924. DOI: 10.22301/IJHMCR.2528-3189.920.

8. Kurek J, Bartkowiak G, Jankowski W, Kwasniewski-Sip P, Schroeder G, Hoffmann M, Barczyński P. Human body fluid ions in colchicine complexes ESI MS, MADLI MS, spectroscopic, DFT studies and fungicidal activity of colchicine complexes with sodium, potassium, magnesium and calcium carbonates and sulphates. IOSR Journal of Pharmacy. 2016, 6(8), 40-55. DOI: 10.9790/3013-068024055.

9. Kurek J, Barczyński P. Colchicine complexes with lithium, sodium and potassium saltsspectroscopic studies. Croatica Chemica Acta. 2016, 89(3), 297-308. DOI: 10.5562/cca2871.

10. Kurek J, Bartkowiak G, Nowakowska Z. Mass spectrometric study of colchicine and its synthetic derivatives 10-alkylthiocolchicines. Acta Chimica Slovenica. 2015, 62(3), 605-616. DOI: 10.17344/acsi.2014.1125.

11. Wang Y, Zhang H, Gigant B, Yu Y, Wu Y, Chen X, Yang J. Structures of a diverse set of colchicine binding site inhibitors in complex with tubulin provide a rationale for drug discovery. The FEBS. 2016, 283(1), 102-111. DOI: 10.1111/febs.13555.

12. Digbeth N, Lauterio TJ, Wolfe HR. Mechanism of action of colchicine in the treatment of gout. Clinical Therapeutics. 2014, 36(10), 1465-1479. DOI: 10.1016/j.clinthera.2014.07.017 
13. Kurek JK. Cytotoxic colchicine alkaloids: from plants to drugs. 2018. DOI: 10.5772/ intechopen.72622.

14. Davis M, Wason S, DiGiacinto J. Colchicine-antimicrobial drug interactions: what pharmacists need to know in treating gout? The Consultant Pharmacist ${ }^{\circledR}$. 2013, 28(3), 176-183. DOI: 10.4140/ TCP.n.2013.176.

15. Padeh S, Gerstein M, Berkun Y. Colchicine is a safe drug in children with familial Mediterranean fever. The Journal of Paediatrics. 2012, 161(6), 1142-1146. DOI: 10.1016/j.jpeds.2012.05.047.

16. Sari I, Birlik M, Kasifoglu T. Familial Mediterranean fever: an updated review. European Journal of Rheumatology. 2014, 1(1), 21. DOI: 10.5152/eurjrheum.2014.006.

17. Taylor TH, Mecchella JN, Larson RJ, Kerin KD, MacKenzie TA. Initiation of allopurinol at first medical contact for acute attacks of gout: a randomized clinical trial. The American Journal of Medicine. 2012, 125(11), 1126-1134. DOI: 10.1016/j.amjmed.2012.05.025.

18. Jankowski W, Kurek J, Barczynski P, Hoffmann M. Quantum-chemical, NMR, FT IR, and ESI MS studies of complexes of colchicine with Zn (II). Journal of Molecular Modeling. 2017, 23(4), 127. DOI: 10.1007/s00894-017-3306-z.

19. Rasheed K, Sultana N, Tariq MI, Ahmad SA, Munir C. Synthesis, characterization and biological studies of metal complexes of an oral hypoglycemic sulfonylurea drug, glibenclamide. Science International.2015,27(3),2127-2132.https:/www.tib.eu/en/search/id/BLSE\%3ARN604344035/ ADAPTIVE-NEURO-FUZZY-INFERENCE-SYSTEM-ANFIS-MODEL/.

20. Khade BC, Deore PM. Studies on metal complexes of some non-essential amino acids with copper (II). International Journal of Universal Science and Technology. 2018, 03(01), 47-51. http://www.universalprint.org/wp-content/uploads/2018/02/IJUP0229.pdf.

21. Majcher U, Klejborowska G, Moshari M, MajE, WietrzykJ, Bartl F, Huczyński A. Antiproliferative activity and molecular docking of novel double-modified colchicine derivatives. Cells. 2018, 7(11), 192. DOI:10.3390/cells7110192. 